\title{
A large outbreak of shigellosis commencing in an internally displaced population, Papua New Guinea, 2013
}

Edwin Benny, ${ }^{a}$ Kelly Mesere, ${ }^{a}$ Boris I Pavlin, ${ }^{b}$ Logan Yakam, ${ }^{c}$ Rebecca Ford, ${ }^{d}$ Mition Yoannes, ${ }^{d}$ Debbie Kisa, ${ }^{d}$

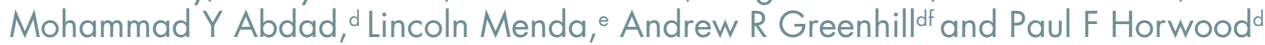

Correspondence to Paul F Horwood (e-mail: paul.horwood@hotmail.com).

Objective: The objective of this study was to investigate a large outbreak of shigellosis in Papua New Guinea that began in a camp for internally displaced persons before spreading throughout the general community.

Methods: Outbreak mitigation strategies were implemented in the affected area to curtail the spread of the disease. Data were collected from the surveillance system and analysed by time, place and person. Rectal swab samples were tested by standard culture methods and real-time polymerase chain reaction to determine the etiology of the outbreak.

Results: Laboratory analysis at two independent institutions established that the outbreak was caused by Shige/la sp., with one strain further characterized as Shigella flexneri serotype 2. Approximately 1200 suspected cases of shigellosis were reported in a two-month period from two townships in Morobe Province, Papua New Guinea. The outbreak resulted in at least five deaths, all in young children.

Discussion: This outbreak of shigellosis highlights the threat of enteric diseases to vulnerable populations such as internally displaced persons in Papua New Guinea, as has been observed in other global settings.

S higellosis (bacillary dysentery) is a major cause of morbidity and mortality, particularly in developing countries. The number of Shigella infections throughout the world annually has been estimated at more than 160 million cases, with more than 1 million deaths. The majority of these cases (> 60\%) and deaths (> 70\%) occur in children younger than five years. ${ }^{1}$ The disease is endemic in most developing countries and caused by four species of Shigella, which are classified based on biochemical and serological differences: Shigella dysenteriae, S. flexneri, S. boydii and S. sonnei. Shigellosis is typically spread through the faecal-oral route by person-to-person contact or through contaminated food or water. It is a known risk among refugees and internally displaced persons (IDPs). ${ }^{2}$ The infectious dose of Shigella can be as low as 10 organisms, ${ }^{3}$ thus facilitating the rapid spread of the organism during outbreaks. The symptoms of shigellosis include fever, watery diarrhoea, abdominal cramps and bloody stools with mucus.
In this study we report on the epidemiological and laboratory findings of a large outbreak of shigellosis which commenced in a settlement camp for IDPs before spreading throughout the general community in Morobe Province, Papua New Guinea. An outbreak investigation was initiated following reports of numerous cases of gastrointestinal disease in a settlement camp in Morobe Province, Papua New Guinea in September 2013. The settlement camp was established following tribal fighting between two neighbouring groups, the Watut and Bupu Garaina people; the Bupu Garaina people were internally displaced following the conflict.

\section{METHODS}

The outbreak was first reported in late September 2013 from a health centre close to the settlement camp near the township of Bulolo, Morobe Province. Over the next two weeks, more than 300 cases of diarrhoea and

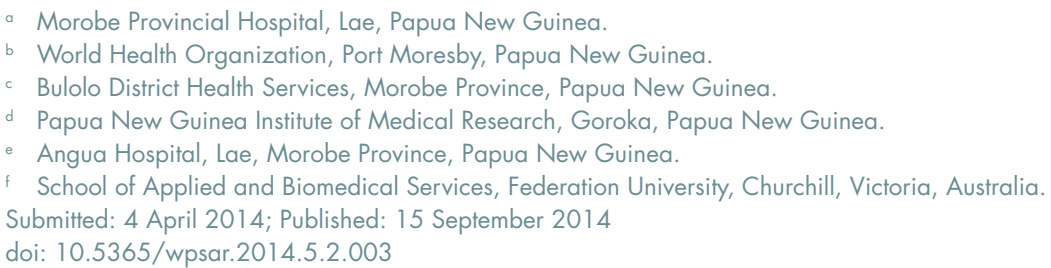


dysentery were recorded at the health centre in close proximity to the camp. Over the subsequent weeks, the outbreak spread to the township of Bulolo and then to the nearby township of Wau, which is located approximately $50 \mathrm{~km}$ away. The case definition for this outbreak was clinic attendees with acute watery and loose stools (with or without mucus and blood) and with or without fever. Detailed line lists were compiled from representative patients to include age, sex, onset date, presentation date, residence, clinical symptoms, outcome and laboratory results. Data were analysed in Microsoft Excel 2010.

Following the initial reports of the outbreak, local and provincial health teams were mobilized and outbreak mitigation strategies were implemented:

- A temporary ban was issued for all cooked-food and ice-block sales in Bulolo township.

- Treatment points were established at the health centre near the camp and other hotspot areas.

- Temporary toilets were built for the care centre.

- Stocks of necessary medications were filled for the affected health clinics.

- Appropriate treatment was advocated using standard treatment guidelines ${ }^{2}$ including aggressive therapy with oral rehydration solution (ORS) for mild diarrhoeal cases.

- A health education and awareness campaign was conducted to promote healthy practices.

- An inspection of hygiene, water and sanitation was conducted in Bulolo township shops and markets to ensure businesses and the general public were complying with hygiene practices stated in the Public Health Act.

Rectal swabs were collected and stored in CaryBlair medium and sent to the Angau Memorial Hospital (Lae, Morobe Province) and the Papua New Guinea Institute of Medical Research (Goroka, Eastern Highlands Province) for bacterial culture analysis using standard methods as outlined by the World Health Organization. Samples were also tested for Shigella spp. using a previously published real-time polymerase chain reaction (PCR) assay. ${ }^{4}$
The public health activities and laboratory testing outlined in this study were organized by the Ministry of Health and Morobe Provincial Health Authority as part of routine outbreak investigation procedures, and as such have a standing authorisation from the National Ethics Committee. All samples were anonymised for the purpose of this study.

\section{RESULTS}

An increase in cases of dysentery and diarrhoea was first recorded at the Bulolo Health Centre in the last week of September 2013 (Figure 1). By the end of the first week of October, over 20 cases of dysentery/diarrhoea were being reported at the clinic per day. In the second week of October cases began presenting at the Wau Health Centre. Dysentery/diarrhoea cases continued to be reported from both Bulolo and Wau until the first week of November. Overall, approximately 1200 cases of diarrhoea and dysentery were reported from the Bulolo/Wau area. The majority of cases were recorded at the Bulolo Health Centre (approximately 900), with the remaining cases recorded at the Wau Health Centre (approximately 300). A detailed line list from randomly selected patients was compiled for 510 cases from the outbreak (Bulolo-368; Wau-142) and the remaining cases were reported as aggregated data.

The outbreak resulted in five deaths (three in Bulolo and two in Wau), with a case fatality proportion of approximately $0.4 \%$. All of the deaths occurred in children under five years of age, and pre-existing morbidities and late presentation to health clinics were believed to be important factors in all of the deaths. There were unconfirmed reports of additional deaths that were not recorded due to the remoteness of the outbreak region.

Among the cases for whom age was recorded ( $n=496)$, the majority were in children: over $70 \%$ of age-reported cases were in children less than 15 years of age with a large proportion less than five years of age. Children less than five years old accounted for $58.3 \%$ ( $n=289$ ) of cases; children five to 14 years: $13.1 \%$ ( $n=65)$; people aged $15-50$ years: $25.0 \%(n=124)$; and older adults more than 50 years: $3.6 \%(n=18)$. Males were more commonly recorded with dysentery/ diarrhoea symptoms during the outbreak, constituting $54.3 \%$ of cases. However, there was no statistical difference in male-female cases. 
Figure 1. Epidemic curve from the shigellosis outbreak in Bululo, September to November 2013

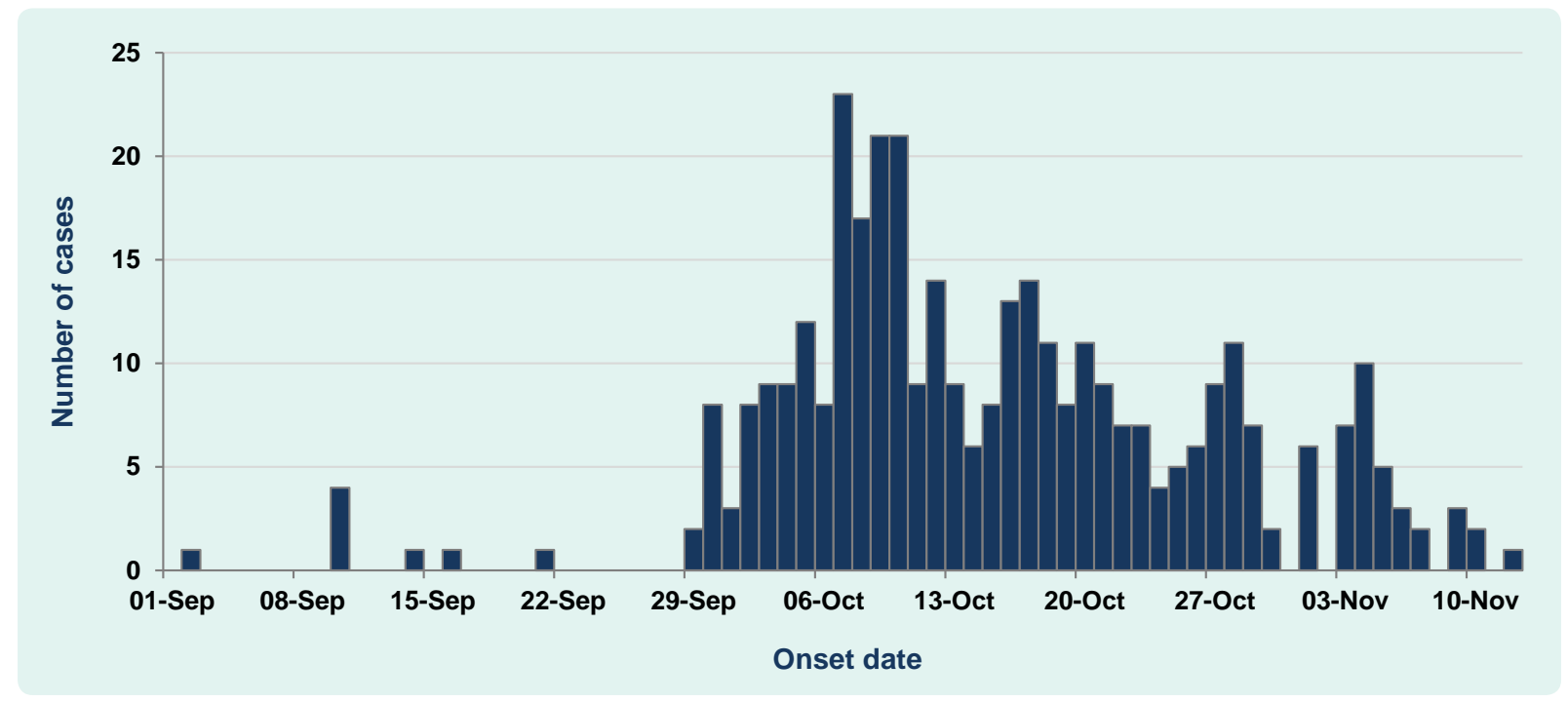

Note: The data are based on 358 patients for whom date of onset was recorded.

Shigella sp. was isolated from four out of six stool samples analysed at the Angau Memorial Hospital laboratory. Shigella sp. was also isolated from one out of 11 stool samples analysed at the Papua New Guinea Institute of Medical Research. This isolate was subsequently serotyped as S. flexneri serotype 2 using Shigella antisera (Denka Seiken Co. Ltd, Tokyo, Japan). In addition, three of the 11 samples tested positive for Shigella sp. using real-time PCR. The sample from which the $S$. flexneri strain was isolated was one of the positive samples. The S. flexneri isolate was archived and will be used for genomic analysis to further characterize the outbreak strain.

With the assistance of the police and town council, the communities heeded the ban on sales of ice blocks and cooked food. The ORS treatment points were maintained until no more cases were reported. Toilets were built for the care centres, and several IDPs were voluntarily repatriated to their home villages. An awareness task force led by the officer-in-charge of the Bulolo Health Centre covered all of the hamlets and sections of the towns with prevention messages on the Five Fs (Food, Fingers, Fluid, Faeces, Flies). Shops and fast food outlets not conforming to the standards and instructions issued by environmental health officers were given notice and followed up until they complied.

\section{DISCUSSION}

In this paper we report on a large outbreak of shigellosis that commenced in a settlement camp for IDPs before spreading to the surrounding community and another township in the same area. The outbreak resulted in approximately 1200 cases of suspected shigellosis, which is one of the largest outbreaks reported in the literature.

This outbreak highlights the threat of shigellosis to vulnerable populations. At particular risk are displaced persons, refugees and people in institutional settings. However, as the spread of this outbreak to the broader community illustrates, much of the population-at-large is at risk of shigellosis. Papua New Guinea has one of the lowest rates of access to safe water and sanitation in the Western Pacific Region. ${ }^{5,6}$ In this instance, the outbreak originated in a settlement camp for displaced persons; however, the rapid spread of the disease throughout the general community is an indication that improvements are needed in the delivery of basic services. The recent country-wide outbreak of cholera is further evidence of the impact that enteric diseases can have on regions where there is inadequate access to safe water and sanitation. ${ }^{7}$ Improvements in safe water and sanitation, though often challenging to implement and maintain in remote, resource-poor settings, need to be prioritized. ${ }^{8}$

Shigella has been established as an important cause of disease in Papua New Guinea. In a recent study in the highlands of the country, Shigella was isolated from $22 \%$ of patients (adults and children) presenting to an urban clinic or hospital outpatients with diarrhoea/dysentery; with S. flexneri the most common species detected. ${ }^{9}$ Similarly, a molecular-based study detected Shige/la as 
the most common pathogen in children (less than five years old) hospitalized with acute watery diarrhoea in the same setting. ${ }^{10}$ An outbreak of shigellosis, attributed to $S$. flexneri serotype 3 , was reported in a remote region of Papua New Guinea in 2009, complicated by a concurrent outbreak of H3N2 influenza. ${ }^{11}$ These findings are of great importance given the lack of a vaccine to prevent infection with Shige/la and the increasing antibiotic resistance of Shigella globally, including Papua New Guinea. ${ }^{9,12}$

In this study, the low isolation and detection rates of Shigella from outbreak samples were probably due to the extended time between sample collection and laboratory testing (more than a week). The logistical issues of transporting clinical material in Papua New Guinea have been noted previously during recent outbreaks of cholera, ${ }^{13}$ shigellosis ${ }^{11}$ and chikungunya. ${ }^{14}$ Incomplete road networks and the paucity of diagnostic laboratories commonly hamper disease outbreak investigations. However, the isolation of Shigella from independent sampling and testing from two laboratories confirm that Shigella sp. was the etiological agent of the outbreak. During the shigellosis outbreak, fragile health care systems and poorly equipped clinics were further stretched by the increase in cases. Although this resulted in suboptimal completion of line lists and may affect the representativeness of the data, we are confident that the results presented in this paper are an accurate description of the shigellosis outbreak in this region. Further studies to fully understand the epidemiology of shigellosis are required in Papua New Guinea with the hope that control strategies can be developed.

\section{Conflicts of interests}

None declared.

\section{Funding}

None.

\section{Acknowledgements}

The authors thank the staff from the Bulolo and Wau Health Centres and the general community from the two townships for their assistance with our investigations. Field investigations and outbreak mitigation measures were conducted with support from the Government of Papua New Guinea, the Morobe Provincial Health
Authority and the World Health Organization. Laboratory investigations at the Papua New Guinea Institute of Medical Research were supported by the Internal Competitive Research Award Scheme from the Government of Papua New Guinea.

\section{References}

1. Kotloff KL et al. Global burden of Shigella infections: implications for vaccine development and implementation of control strategies. Bulletin of the World Health Organization, 1999, 77:651-666. pmid: 10516787

2. Guidelines for the control of shigellosis, including epidemics due to Shigella dysenteriae type 1. Geneva, World Health Organization, 2005 (http://whqlibdoc.who.int/publications/2005/9241592330. pdf, accessed 29 January 2014).

3. DuPont HL et al. Inoculum size in shigellosis and implications for expected mode of transmission. Journal of Infectious Diseases, 1989, 159:1126-1128. doi:10.1093/infdis/159.6.1126 pmid:2656880

4. Lin WS, Cheng CM, Van KT. A quantitative PCR assay for rapid detection of Shigella species in fresh produce. Journal of Food Protection, 2010, 73:221-233. pmid:20132666

5. National Health Plan 2001-2010: Health Vision 2010. Policy Directions and Priorities. Vol. 1. Port Moresby, Papua New Guinea Ministry of Health, 2000.

6. World Health Organization, United Nations Children's Fund Joint Monitoring Programme for Water Supply and Sanitation. Estimates for the use of improved sanitation facilities, Papua New Guinea. New York, United Nations Children's Fund, 2010 (http://www.unicef.org/infobycountrypapuang_statistics. html, accessed 14 November 2011).

7. Horwood PF et al. Clonal origins of Vibrio cholerae $\mathrm{O} 1 \mathrm{El}$ Tor strains, Papua New Guinea, 2009-2011. Emerging Infectious Diseases, 2011, 17:2063-2065. doi:10.3201/eid1711.110782 pmid:22099099

8. Horwood PF, Greenhill AR. Cholera in Papua New Guinea and the importance of safe water sources and sanitation. Western Pacific Surveillance and Response Journal, 2012, 3:3-5. doi:10.5365/ wpsar.2011.2.4.014 pmid:23908900

9. Greenhill AR et al. Antibiotic resistant Shigella is a major cause of diarrhoea in the Highlands of Papua New Guinea. Journal of Infection in Developing Countries. In press.

10. Soli $\mathrm{KW}$ et al. Detection of enteric viral and bacterial pathogens associated with paediatric diarrhoea in Goroka, Papua New Guinea. International Journal of Infectious Diseases, 2014: pii: S12019712(14)01463-5. In press. doi:10.1016/j.ijid.2014.02.023 pmid:25193391

11. Rosewell $A$ et al. Concurrent influenza and shigellosis outbreaks, Papua New Guinea, 2009. Emerging Infectious Diseases, 2011, 17:756-758. doi:10.3201/eid1706.101021 pmid:21470485

12. Rosewell A et al. Shigella spp. antimicrobial drug resistance, Papua New Guinea, 2000-2009. Emerging Infectious Diseases, 2010, 16:1797-1799. doi:10.3201/eid1611.101025 pmid:21029550

13. Greenhill AR et al. Improved laboratory capacity is required to respond better to future cholera outbreaks in Papua New Guinea. Western Pacific Surveillance and Response Journal, 2012, 3:3032. doi:10.5365/wpsar.2011.2.4.016 pmid:23908909

14. Horwood PF et al. Outbreak of chikungunya virus infection, Vanimo, Papua New Guinea. Emerging Infectious Diseases, 2013, 19:1535-1538. doi:10.3201/eid1909.130130 pmid:23965757 